\title{
EFFECTS OF SOURCE CREDIBILITY ON THE RELATIONSHIP BETWEEN AUTHORITARIANISM AND ATTITUDE CHANGE
}

\author{
HOMER H. JOHNSON, JAMES M. TORCIVIA, AND MARY ANN POPRICK
}

\author{
Loyola University, Chicago
}

\begin{abstract}
Persuasive messages attributed to either a high credible or a low credible source were presented to Ss who varied in F Scale ("authoritarianism") scores. A significant interaction appeared between $\mathbf{F}$ Scale scores and source credibility with respect to attitude change, indicating the low $F$ scorer to be more influenced by source differences than the high $F$ scorer. These data are interpreted as supporting McGuire's general model for the relationship between persuasibility and personality, and refuting Johnson and Steiner's hypothesis that the high $F$ scorer is "source-oriented." Extension of these findings to social conformity studies is discussed.
\end{abstract}

Jolnnson and Steiner (1967) have proposed an explanation to account for the relationship between authoritarianism and attitude change or conformity. These authors suggest that the high authoritarian is oriented to (or dependent upon) the source of the message, and his propensity for attitude change is directly related to the credibility or attractiveness of the source, with only secondary regard for the message content. The low authoritarian, on the other hand, is more oriented to the content of the message relative to the source (Adorno, Frenkel-Brunswik, Levinson, \& Sanford, 1950). If the authoritarian is "sourceoriented," then a significant interaction effect should appear between authoritarianism and the message source such that the high authoritarian shows more fluctuation than the low authoritarian in attitude change as a function of the difference in source credibility.

An alternative, and conflicting, explanation can be found in McGuire's (1968; Nisbett \& Gordon, 1967) recent treatment of the relationship between personality variables and persuasibility. McGuire views attitude change as an outcome of the chain of processes which include a reception component (i.e., attention and comprehension of the message) and a yielding component. To predict the relationship between attitude change and a personality variable, one must consider the relationship between the personality variable and each of these components separately. If the

1 This research was supported by National Science Foundation Grants GS-932 and GS-1329 to the senior author. personality variable is directly related to yielding and inversely related to comprehension, then a general nonmonotonic relationship exists between the personality variable and attitude change such that the point of maximum attitude change occurs at an intermediate level of the personality variable. This optimal level of the personality variable for attitude change moves up or down depending on the situational factors that affect reception (e.g., message difficulty), or yielding (e.g., source credibility). Higher source credibility raises the elevation of the yielding gradient which in turn lowers the personality level that is optimal for producing attitude change.

Applying the McGuire model to the relationship between authoritarianism and attitude change, the evidence seems to indicate that scores on the F Scale measure of authoritarianism are directly related to yielding and inversely related to comprehension (Peabody, 1966). Given a moderately difficult message from a low credible source it is reasonable to assume that the elevation of the yielding gradient would be quite low, and the point at which it intersects with the reception gradient would be at a high level of the $F$ Scale. Thus attitude change in this case would tend towards a positive monotonic function of $F$ scores. Attributing the same message to a high credible source would raise the elevation of the yielding gradient, and thus the intersect of the two gradients would be at a lower F Scale level. Attitude change in this latter case would be maximum at a moderate or, 
more probably, a low $\mathrm{F}$ level. If the above assumptions are valid, attitude change for the high authoritarian (i.e., high $\mathrm{F}$ scorer) should be relatively unaffected by the change in source credibility. He would yield to the extent of his reception under both high and low source conditions. Rather, it is the moderate or low $\mathrm{F}$ scorer who is most affected by changes in source credibility. This prediction is, of course, opposite to that hypothesized by Johnson and Steiner. ${ }^{2}$

The experiment presented in this paper manipulates the credibility of the source of the influence attempt and examines the effects of this variable on the relationship between $F$ Scale scores and attitude change. Johnson and Steiner as well as McGuire predicted an interaction between $\mathbf{F}$ Scale scores and source credibility. To the extent that the high authoritarian is "source-oriented," as Johnson and Steiner have suggested, then the high F scorer should be more susceptible to gross differences in source factors than the low $F$ scorers. However, if McGuire's general model is valid, the opposite trend should be found.

\section{METHoD}

\section{Design and Subjects}

A $2 \times 2$ experimental design was used with subjects receiving a communication against the use of chest $\mathrm{X}$ rays for the detection of tuberculosis or against frequent toothbrushing. The communication was attributed to either a high credible or a low credible source. Subjects also responded to the $F$ Scale. Of experimental interest in this study is the relationship between the personality variable and attitude change in each of the four treatment groups.

The subjects were 152 male and female students attending the introductory psychology course at Loyola University in the evening and summer school sections. They constituted a rather heterogeneous sample, including full-time students, businessmen, store clerks, secretaries, priests and nuns, etc. Sub-

2 Two points are to be noted here with regard to the McGuire theory. First, we are making the assumption that source credibility affects only the elevation of the yielding gradient and has no effect on the slope of the gradient. Secondly, McGuire (1968) has also raised the possibility of a situational interaction between $F$ Scale scores and the source of an influence attempt. High $F$ scores would be more affected by source factors where the sources lay on different sides of the neutral point, while low $F$ scorers would tend to be more sensitive to differences between sources lying on the same side of the neutral point. jects were tested during their regularly scheduled class periods.

First session. During the first session subjects were given a test booklet, the first page of which contained a 17-item questionnaire designed by McGuire (1961) to assess attitudes on a variety of medically related "cultural truisms"; for example, use of penicillin, $X$ rays, toothbrushing, etc. These issues were chosen because almost without exception persons have highly favorable attitudes toward these practices. The subjects then read a 120-word biographical statement about the source of the communication they were to read next. One of the biographical statements described the source as a medical authority who was recognized as an expert on the issue of concern in the communication. The other described the source as a medical quack who had served a prison term for medical fraud and who knew nothing substantial about the issue, but had only written the communication for a magazine catering to sensationalism. The subjects then responded to a scale designed to assess their impressions of the source's credibility on the issue. This was a nine-position scale ranging from "I would consider him completely incompetent to render an opinion on this matter" to "I would accept his judgment on this matter without question." A 600 word communication, attributed to the source and arguing against either annual chest $\mathrm{X}$ rays or frequent toothbrushing, was then read by each subject. The communications were similar to those used in the McGuire studies.

After reading the communication subjects responded to a four-item questionnaire that was designed to assess their attitudes on the issue discussed in the communication (either chest $X$ rays or toothbrushing). These four items were taken directly from the initial 17-item questionnaire and dealt only with the issue relevant to that discussed in the communication. In this questionnaire, statements such as "Chest $X$ rays for $T B$ should be taken regularly and often" are presented, and the respondent indicates his degree of agreement with each statement on a 15-point bipolar scale.

In the final part of the booklet subjects filled out a questionnaire designed to assess their recall of the communication. This questionnaire consisted of 12 sentences taken from the communication. Parts of these sentences were omitted and subjects were asked to recall the missing words or phrases.

To insure as random an assignment of subjects to treatments as possible, the test booklets representing the four treatments were "shuflled" before they were passed out to the subjects. Thus, within the limits of the design, the assignment of subjects to treatments was random, and the experimenter had no knowledge of which subjects had been assigned to which treatments.

Second session. The second session was held 7 days after the first. To minimize the subjects' connecting the two sessions, a different experimenter was used, and the subjects were told that the experimenter was gathering some data on test construction. Sub- 
TABLE 1

Eftects of Source Manipulation on Source Rating, Attitude Scores, and Recail Scores

\begin{tabular}{l|c|c|c|c|c|c|c}
\hline \hline & $N$ & Source rating & $\begin{array}{c}\text { Initial } \\
\text { attitude }\end{array}$ & $\begin{array}{c}\text { Postmessage } \\
\text { attltude }\end{array}$ & $\begin{array}{c}\text { Delayed } \\
\text { attitude }\end{array}$ & $\begin{array}{c}\text { Immediate } \\
\text { recall }\end{array}$ & $\begin{array}{c}\text { Delayed } \\
\text { recall }\end{array}$ \\
\hline High source (X ray) & 36 & 7.47 & 46.61 & 23.56 & 22.42 & 12.17 & 9.05 \\
Low source (X ray) & 40 & 3.03 & 46.90 & 36.35 & 39.00 & 10.68 & 7.80 \\
High source (tooth) & 39 & 7.51 & 42.33 & 29.56 & 30.56 & 13.41 & 11.72 \\
Low source (tooth) & 37 & 2.81 & 45.22 & 41.38 & 42.03 & 12.87 & 10.22 \\
\hline
\end{tabular}

jects filled out a test booklet which contained several questionnaires including Form $45-40$ of the California F Scale (Adorno et al., 1950) with one item deleted (No. 22) because of its irrelevance to contemporary society. In addition, subjects again indicated their attitudes toward the issues used in the communication on the four-item scale used in the first session, and the final page of the booklet contained the recall test also given in the first session, thus wording delayed measures of attitude change and recall. At the end of the second session the subjects were given an explanation of the study.

\section{Results}

Effects of source manipulations. Table 1 reports the effects of the source manipulation in the four treatment categories. Initial ratings of source competency were made on a 9-point scale with 9 being the most favorable score possible. Subjects' ratings of source were significantly higher $(p<.001)$ in the high credible source (HS) treatment than in the low credible source (LS) treatment for both the X-ray issue $(t=10.01)$ and the toothbrushing issue $(t=11.19)$. Attitudes toward issue reported in Table 1 are mean scores over the four items. Sixty $(4 \times 15)$ is the most favorable score possible. Results indicate (a) no significant differences between the HS and LS treatments with regard to initial attitudes for either the X-ray $(t=.13)$ or toothbrushing $(t=.59)$ issues; $(b)$ significantly $(p<.01)$ more yielding (i.e., lower scores) to the HS than the LS on posttreatment attitudes for both the X-ray $(t=3.42)$ and toothbrushing $(t=3.17)$ issues, and $(c)$ significantly $(p<.01)$ more yielding to HS than LS on delayed attitude measures for both the X-ray $(t=3.03)$ and toothbrushing $(t=3.15)$ issues.

Table 1 also reports the mean recall scores. For each of the two issues there were 25 blanks to be completed in the 12 partial sentences. A score of 25 indicates perfect recall. The results indicate (a) no significant differ- ences in immediate recall for the HS treatment and the LS treatment for either the X-ray $(t=.97)$ or toothbrushing $(t=.42)$ issues, and $(b)$ no significant differences in delayed recall for the HS and LS treatments for either the X-ray $(t=.76)$ or the toothbrushing $(t=1.01)$ issues.

Effects of $F$ scores. One purpose of the recall measure was to test the assumption (relevant to the McGuire model) that $\mathrm{F}$ scores are inversely related to comprehension. The average correlation (across the four treatments) between $\mathrm{F}$ and immediate recall was $-.23(p$ $<.01, d f=140)$ and $-.26(p<.01, d f=$ $140)$ for delayed recall. Thus this assumption appears valid.

The relationship between $\mathrm{F}$ scores, source credibility, and attitude change is presented in Table 2. For this analysis subjects were categorized either in the upper quarter, middle half, or lower quarter on the basis of the total sample of $F$ scores $(N=152)$. Table 2 reports the mean change of attitude scores for the three groups of subjects for the immediate attitude change measure. The attitude change results in Table 2 indicate that the high $F$ scorers were least affected by the source manipulation, those with intermediate $F$ scores

TABLE 2

Mean Immediate Attitude Change Scores for F Groupings aNd Issurs

\begin{tabular}{c|c|c|c|c}
\hline & \multicolumn{2}{|c|}{ X-ray issue } & \multicolumn{2}{c}{ Toothbrushing issue } \\
\cline { 2 - 5 } & $\begin{array}{c}\text { High } \\
\text { source }\end{array}$ & $\begin{array}{c}\text { Low } \\
\text { source }\end{array}$ & $\begin{array}{c}\text { High } \\
\text { source }\end{array}$ & $\begin{array}{c}\text { Low } \\
\text { source }\end{array}$ \\
\hline High F & 20.33 & 16.18 & 7.33 & 5.89 \\
$N$ & 9 & 11 & 9 & 9 \\
Medium F & 23.76 & 10.00 & 13.14 & 6.47 \\
$N$ & 21 & 16 & 22 & 17 \\
Low F & 24.67 & 6.46 & 17.88 & 1.27 \\
$N$ & 6 & 13 & 8 & 11 \\
\hline
\end{tabular}

Note.-The higher the score, the greater the attitude change. 
were more affected by the source, and the low $F$ scorers were most affected. Combining results from both issues (which showed very similar trends), analysis of variance (least squares solution, Winer, 1962) indicated that the main effects of source were highly significant $(F=25.70)$, and the main effect for $F$ level was not significant $(F=.26)$. The theoretically crucial interaction effect between source and $\mathrm{F}$ score was significant $(F=$ $3.30, p<.05, d f=2,145)$. Using Kramer's (1956) multiple-range test for unequal $\mathrm{Ns}$, it was found that no significant differences appeared between the two high $F$ groups, but both the middle $\mathrm{F}$ and the low $\mathrm{F}$ groupings differed significantly $(p<.001)$. Similar trends were found on the delayed measures of attitude.

\section{Discussion}

The results suggest several conclusions of theoretical interest. First, with respect to the effects of source credibility on recall and attitude change, the data presented in Table 1 indicate, as did earlier research by Hovland (Hovland, Janis, \& Kelley, 1953, p. 37), that if the source is clearly of high or low credibility, source credibility does not affect the subject's attention to, or comprehension of, the message. Rather, source credibility appears to have its major effect on the subject's propensity to accept the conclusions of the message.

Secondly, with regard to the $F$ Scale, no support was found for the Johnson and Steiner hypothesis that the high $\mathrm{F}$ scorer is source oriented and would show more fluctuation in attitude change as a function of the change in source credibility than would the low F scorer. The results indicate the opposite effect and are interpreted as supporting McGuire's general model.

Another finding of theoretical interest is that the relationships between the $F$ scores and attitude change for the two sources and two issues showed similar trends for both the immediate and delayed attitude change measures. This latter finding is contrary to the hypothesis advanced by Johnson and Steiner who suggested that attitude change for the high $\mathrm{F}$ scorer may be simply a temporary acquiescence without conviction. The data of this study indicate that attitude change appears no more or less temporary for the high F scorer than for the low F scorer, at least as measured 1 week after the initial change. The Johnson and Steiner hypothesis was based on evidence from a social conformity situation, and although it was not supported in the study presented here, the possibility still remains for its confirmation in social pressure situations.

The explanation of the high $F$ scorer being source oriented was, to a great extent, based on findings from the social conformity area. Although McGuire's model seems to account for the attitude change results presented here, a crucial test of the generality of the model is whether or not it can account for the findings of the social conformity experiments. Positive correlations between $\mathrm{F}$ scores and conformity have generally been found in the Asch-type situation in which there is unanimity of confederates to clearly erroneous judgments (e.g., Canning \& Baker, 1959; Crutchfield, 1955; Nadler, 1959; Steiner \& Johnson, 1963; Wells, Weinert, \& Rubel, 1956). When the social pressure is reduced by a break in unanimity or when there is a single source, the correlations between $F$ and conformity are essentially zero (Steiner \& Vannoy, 1966; Weiner \& McGinnies, 1961; see Malof \& Lott, 1962, for the same trend with the $\mathrm{E}$ Scale). This latter relationship can be explained by the fact that there is little or no conformity (except to obviously valid judgments), and thus no conformity variance need be accounted for. However, the former relationship seems to indicate that the high $\mathrm{F}$ scorer is susceptible to social pressure. In relating the McGuire model to this experimental situation, it would be hypothesized that the reception gradient is of little consequence as the "message" is quite simple and easily understood so that there is negligible individual difference. The yielding gradient is the important determiner of the relationship between a personality variable and conformity. Since the yielding gradient is positively related to the $F$ Scale scores, the high F scorer should conform more than the low F scorer, and the bulk of the experimental evidence supports this expectation. 


\section{REFERENCES}

Adorno, T. W., Frenkel-Brunswir, E., Levinson, D. J., \& SANFoRd, R. N. The authoritarian personality. New York: Harper, 1950.

Canning, R. R., \& Baker, J. M. Effect of the group on authoritarian and non-authoritarian persons. American Journal of Sociology, 1959, 64, 579-581.

Crutchrield, R. S. Conformity and character. American Psychologist, 1955, 10, 191-198.

Hovland, C. I., Janis, I. L., \& Kelley, H. H. Communication and persuasion. New Haven: Yale University Press, 1953.

Johnson, H. H., \& Steiner, I. D. Some effects of discrepancy level on relationships between authoritarianism and conformity. Journal of Social Psychology, 1967, 73, 199-204.

KRAMER, C. Y. Extension of multiple range tests to group means with unequal numbers of replications. Biometrics, 1956, 12, 307-310.

MaLOF, M., \& LOTT, A. J. Ethnocentrism and the acceptance of Negro support in a group pressure situation. Journal of Abnormal and Social Psychology, 1962, 65, 254-258.

MCGuIRE, W. J. Resistance to persuasion conferred by active and passive prior refutation of the same and alternative counterarguments. Journal of $A b$ normal and Social Psychology, 1961, 63, 326-332.
McGuIRE, W. J. Personality and susceptibility to social influence. In E. F. Borgatta \& W. W. Lambert (Eds.), Handbook of personality theory and research. Chicago: Rand McNally, 1968, in press. NADLER, E. B. Yielding, authoritarianism and authoritarian ideology regarding groups. Journal of $A b$ normal and Social Psychology, 1959, 58, 408-410.

Nisbetr, R. E., \& GoRdon, A. Self-esteem and suceptibility to social influence. Journal of Personality and Social Psychology, 1967, 5, 268-276.

PEABODY, D. Authoritarianism scales and response bias. Psychological Bulletin, 1966, 65, 11-23.

Sterner, I. D., \& JoHnson, H. H. Authoritarianism and conformity. Sociometry, 1963, 26, 21-34.

Steiner, I. D., \& Vannoy, J. S. Personality correlates of two types of conformity behavior. Journal of Personality and Social Psychology, 1966, 4, 307-315.

Weiner, H., \& McGinnies, E. Authoritarianism, conformity, and confidence in a perceptual judgment situation. Journal of Social Psychology, 1961, 55, 77-84.

Wrtes, W. D., Wetnert, G., \& Ruber, M. Conformity pressure and authoritarian personality. Journal of Personality, 1956, 42, 133-136.

WINER, B. J. Statistical principles in experimental design. New York: McGraw-Hill, 1962.

(Received July 15, 1967) 